\title{
PERAN ORGANIZATIONAL CITIZENSHIP BEHAVIOR SEBAGAI VARIABEL MEDIASI PENGARUH EMOTIONAL INTELLIGENCE TERHADAP KINERJA DI FAKULTAS EKONOMI UNIVERSITAS NEGERI SURABAYA
}

\author{
Inas Khildah Fatmawati \\ Universitas Negeri Surabaya \\ inasfatmawati16080574135@mhs.unesa.ac.id \\ Nurul Indawati \\ Universitas Negeri Surabaya \\ nurulindawati@unesa.ac.id
}

Abstract

\begin{abstract}
The purpose of this study is to analyze the effect of emotional intelligence on performance through organizational citizenship behavior. Respondents in this study were lecturers at the Faculty of Economics, Universitas Negeri Surabaya, and 56 samples were obtained for analysis. The data analysis technique used is a Partial Least Square with SmartPLS 3.0 software. The results show that there is a positive and significant effect between emotional intelligence with performance, emotional intelligence with organizational citizenship behavior, OCB with performance, and emotional intelligence with performance through $O C B$.
\end{abstract}

Keywords: emotional intelligence; organizational citizenship behavior; performance.

\section{PENDAHULUAN}

Sumber daya manusia merupakan aset terpenting bagi suatu institusi. Keberhasilan dalam mencapai visi/ misi, serta tujuan organisasi sangat tergantung pada kinerja SDM yang dimiliki, karena melalui SDM sebuah organisasi dapat memperoleh dan mempertahankan keunggulan kompetitif. Sehingga menjaga dan mengembangkan SDM yang dimiliki menjadi kewajiban bagi setiap organisasi. Ketika seorang individu dalam sebuah organisasi memberikan kinerja yang baik maka akan memberi banyak keuntungan bagi organisasi. Sebaliknya, seorang individu memberikan kinerja yang tidak baik atau kurang produktif maka kerugian akan diterima oleh organisasi. Perbedaan kinerja tiap individu dalam organisasi ini disebabkan oleh perbedaan sikap dan perilaku individu dalam bekerja. (Khanifah \& Palupiningdyah, 2015).

Wati \& Surjanti (2018) menjelaskan bahwa bakat, kualitas, motivasi yang tinggi, serta kemauan untuk bekerja bersama dalam sebuah tim yang dimiliki oleh SDM dari suatu organisasi, merupakan kunci dalam pencapaian keberhasilan sebuah organisasi. Oleh karena itu, penting untuk memperhatikan SDM dengan sebaik mungkin sehingga efisiensi, efektifitas dan produktivitas kerja yang tercermin dalam kinerja SDM tersebut mengalami peningkatan. Kinerja sendiri dapat diartikan sebagai hasil rekaman yang dihasilkan atas aktifitas pekerjaan tertentu dan selama periode tertentu (Bestyasamala, 2018).

Kinerja dari seorang pagawai juga dapat dipengaruhi oleh perilaku karyawan, seperti perilaku yang dengan sukarela memberikan bantuan terhadap rekan kerja untuk menyelesaikan tugas demi tercapainya tujuan organisasi. Perilaku tersebut dapat dikatakan sebagai organizational citizenship behavior (Priyono, et al., 2019). Vipraprastha, et al. (2018) memberikan penjelasan terkait dengan organizational citizenship behavior, di mana hal tersebut dapat diartikan sebagai perilaku inisiatif seorang pekerja untuk melakukan pekerjaan yang bukan menjadi pekerjaan atau deskripsi pekerjaannya, tetapi dia melakukannya secara sukarela tanpa menuntut adanya imbal balik. Hasil penelitian yang dilakukan oleh Razavi \& Attarnezhad (2018) menyebutkan bahwa diantara hubungan variabel OCB dan variabel performance ditemukan adanya pengaruh positif dan signifikan.

Penelitian dari Sharma \& Mahajan (2017) menunjukkan suatu hasil mengenai adanya pengaruh signifikan positif antara emotional intelligence dan OCB. Tingkat emosional dari suatu individu terkait 
Inas Khildah Fatmawati \& Nurul Indawati. Peran Organizational Citizenship Behavior sebagai Variabel Mediasi Pengaruh Emotional Intelligence terhadap Kinerja di Fakultas Ekonomi Universitas Negeri Surabaya

dengan kecerdasan emosional yang dimilikinya. Perbedaan emosional yang dimiliki oleh individu akan memberikan pengaruh terhadap baik atau buruknya individu tersebut dalam melakukan suatu pekerjaan. Kecerdasan emosional adalah kemampuan seseorang yang dapat menerima, memberikan penilaian, melakukan pengelolaan, serta dapat mengontrol emosinya sendiri, dan emosi yang dimiliki oleh orang lain yang berada di lingkugan sekitarnya (Madali, et al., 2014). Penelitian Eze, et al. (2019) membuktikan bahwa emotional intelligence beserta semua komponen yang terkait dengannya, memberikan pengaruh signifikan positif terhadap kinerja.

Universitas merupakan bentuk organisasi yang beroperasi dalam bidang pendidikan. Universitas Negeri Surabaya saat ini memiliki tujuh fakultas. Salah satu fakultas dengan minat yang tinggi di Unesa adalah Fakultas Ekonomi. Sebagai Fakultas yang memiliki jumlah mahasiswa yang besar (unesa.ac.id, 2020), maka kinerja Fakultas Ekonomi harus ditunjang oleh tenaga pendidik (dosen) dan tenaga kependidikan dengan kuantitas dan kualitas yang memadai. Hal tersebut sesuai dengan misi dari Fakultas Ekonomi yang ingin menjadi good faculty governance agar tetap bisa menjamin dan menjaga kepuasan dari pelanggan. Kinerja dosen Fakultas Ekonomi Unesa pada umumnya sudah relatif baik, didukung juga dengan organizational citizenship behavior yang dimiliki olehnya. Akan tetapi banyaknya SDM di Fakultas Ekonomi tentu memiliki karakteristik dan sifat yang berbeda-beda serta kemampuan untuk mengontrol emosi yang berbeda pula, hal tersebut dapat berarti bahwa tingkat emotional intelligence belum sepenuhnya dimiliki oleh seluruh sumber daya manusia yang ada di Fakultas Ekonomi Unesa. Perbedaan tingkat emosional tersebut adakalanya mengakibatkan kinerja dari karyawan tersebut kurang maksimal, yang tentunya hal tersebut juga berdampak pada kurang maksimalnya pemenuhan target yang seharusnya dicapai setiap tahunnya. Tujuan dari studi ini yaitu untuk menguji serta menganalisis pengaruh emotional intelligence terhadap kinerja, emotional intelligence terhadap OCB, OCB terhadap kinerja, serta emotional intelligence terhadap kinerja dengan melalui OCB pada dosen Fakultas Ekonomi Universitas Negeri Surabaya.

\section{KAJIAN PUSTAKA DAN PENGEMBANGAN HIPOTESIS}

\section{Kecerdasan Emosional (Emotional Intelligence)}

Menurut hasil penelitian dari Khan, et al. (2018) emotional intelligence merupakan suatu kemampuan dalam memahami hal-hal terkait dengan emosi, seperti mempersepsikan emosi dari ekspresi wajah, tanda-tanda suara dari individu serta mengetahui keadaan fisik dan mental pribadi yang terkait dengan emosi. Kecerdasan emosional juga bisa dimaknai sebagai kemampuan individu untuk menerima, menilai, mengelola,dan memberikan kontrol pada emosinya sendiri serta emosi orang lain yang ada disekitarnya (Madali, et al., 2014).Widiani (2019) mengungkapkan bahwa emotional intelligence dalam konteks pekerjaan, disebut sebagai kemampuan dalam mengetahui apa yang bisa dirasakan oleh diri sendiri ataupun orang lain (atasan, rekan kerja, bawahan, dan pelanggaran yang dilakukan). Serta penggunaan kemampuan dalam memahami emosi tersebut untuk menyelesaikan suatu permasalahan. Emotional intelligence juga dapat diartikan sebagai kemampuan seseorang dalam melakukan identifikasi, memahami, dan mengelola emosi yang timbul dari diri sendiri serta emosi yang tampak pada diri orang lain secara lebih positif, sehingga individu tersebut dapat terbebas dari stres, dapat berempati dengan orang lain, serta dapat dengan mudah mengatasi tantangan (Luxmi \&Vashisht, 2017). Fokus utama dari emotional intelligence ialah emosi itu sendiri serta cara pengelolaan emosi tersebut dengan tujuan meningkatkan pemikirannya (Eze, et al., 2019).

\section{Organizational Citizenship Behavior}

$O C B$ bisa dimaknai dengan suatu perilaku dari seorang pekerja diluar ketentuan uraian tugas kerjanya. Hal tersebut merupakan kesediaan karyawan untuk melakukan tugas tanpa memperoleh kompensasi khusus (Sharma \& Mahajan, 2017). Seperti halnya yang dinyatakan oleh Hakim \& Pristika (2020), bahwa yang dimaksud dengan organizational citizenship behavior adalah sikap seorang pekerja dalam memberikan bantuan terhadap rekan kerja mereka, di mana orang tersebut bersedia untuk mengerjakan pekerjaan lain di luar deskripsi pekerjaan yang sudah ditentukan oleh organisasi tempat dia bekerja. $O C B$ berarti perilaku sukarela yang dilakukan oleh karyawan. Dilakukan tanpa adanya paksaan dengan tujuan untuk memberikan bantuan terhadap pihak-pihak lain (seperti: rekan kerja, lembaga ataupun 
organisasi), dan bukan untuk kepentingan pribadi. Mereka melakukan pekerjaan bebas di luar tugas formal yang sudah ditetapkan oleh organisasi. Karena dilakukan dengan sukarela, maka tidak ada keterkaitan langsung antara organizational citizenship behavior dengan reward atau kompensasi (Wati \& Surjanti, 2018). Razavi \& Attarnezhad (2018) menyatakan organizational citizenship behavior sebagai perilaku peran ekstra, yang berarti bahwa karyawan bekerja dalam peran ekstra atau dalam kata lain mereka bekerja lebih dari deskripsi pekerjaan formal mereka.

\section{Kinerja}

Kinerja karyawan adalah pencapaian pekerjaan yang dilakukan oleh karyawan, terkait dengan tugas maupun wewenang yang sesuai dengan kemampuan dan kompetensi karyawan baik dari kualitas ataupun kuantitas dalam pencapaian visi, misi, serta tujuan perusahaan (Vipraprastha, et al., 2018). Kinerja dapat dijadikan sebagai tolak ukur tingkat pencapaian dari karyawan, baik secara individual maupun kelompok (Razavi \& Attarnezhad, 2018). Hakim \& Pristika (2020) memaknai kinerja sebagai pencapaian hasil dari seorang karyawan setelah melaksanakan pekerjaan atau tugas mereka. Seperti halnya Noermijati \& Ratri (2018) mendefinisikan kinerja sebagai suatu hasil yang telah dipenuhi oleh setiap pegawai, yang sesuai dengan perilaku kerja dan tujuan kerja pegawai. Kinerja juga dapat diartikan sebagai hasil rekaman yang dihasilkan atas aktifitas pekerjaan tertentu dan selama periode tertentu (Bestyasamala, 2018).

\section{Hubungan antar Variabel}

Lakshmi \& Rao (2018) dalam penelitiannya mengenai hubungan antara faktor-faktor dari emotional intelligence dan Kinerja, menjelaskan bahwa emotional intelligence memiliki dampak langsung terhadap Kinerja. Hasil penelitian lainnya dari Chong, et al. (2020) menunjukkan bahwa emotional intelligence berpengaruh secara positif dan signifikan terhadap Kinerja. Noermijati and Ratri (2018) mengemukakan bahwa emotional intelligence memberikan pengaruh positif serta signifikan terhadap kinerja. Sejalan dengan penelitian yang telah dilakukan oleh Eze, et al. (2019) yang juga menunjukkan suatu hasil bahwasanya pengaruh positif signifikan juga ditemukan pada hubungan kecerdasan emosional terhadap kinerja. Begitupun dengan Khan, et al. (2018) dalam penelitiannya juga menjelaskan suatu hasil terkait dengan adanya hubungan positif diantara indikator emotional intelligence dengan kinerja.

H1: Diduga emotional intelligence berpengaruh positif terhadap kinerja pada dosen Fakultas Ekonomi Universitas Negeri Surabaya.

Sabahi \& Sanai Dashti (2016) menyebutkan bahwa emotional intelligence memberikan pengaruh positif dan signifikan terhadap Organizational Citizenship Behavior. Hakim \& Pristika (2020) dalam penelitiannya juga menemukan bahwa terdapat pengaruh signifikan positif dalam hubungan emotional intelligence terhadap $O C B$. Hasil studi dari Sharma \& Mahajan (2017) menunjukkan bahwa ditemukan adanya pengaruh positif serta signifikan yang diberikan oleh emotional intelligence terhadap variabel $O C B$. Bestyasamala (2018) mengungkapkan suatu hasil tentang adanya pengangaruh signifikan positif antara kecerdasan emosional dengan $O C B$. Aderibigbe \& Mjoli (2018) juga menemukan bahwa kecerdasan emosional berhubungan positif dan signifikan dengan $O C B$.

H2: Diduga emotional intelligence berpengaruh positif terhadap organizational citizenship behavior pada dosen Fakultas Ekonomi Universitas Negeri Surabaya.

Gunay (2018), Hakim \& Fernandes (2017), Razavi \& Attarnezhad (2018), Suwibawa, et al. (2018) serta Priyono, et al. (2019) mengemukakan bahwa $O C B$ berpengaruh positif dan signifikan terhada kinerja. Begitu pula dengan penelitian Chelagat, et al. (2015) menunjukkan hasil bahwa indikator OCB (altruism dan courtesy) berpengaruh positif dan signifikan terhadap kinerja.

H3: Diduga organizational citizenship behavior berpengaruh positif terhadap kinerja pada dosen Fakultas Ekonomi Universitas Negeri Surabaya. 
Inas Khildah Fatmawati \& Nurul Indawati. Peran Organizational Citizenship Behavior sebagai Variabel Mediasi Pengaruh Emotional Intelligence terhadap Kinerja di Fakultas Ekonomi Universitas Negeri Surabaya

Organizational citizenship behavior diketahui memilliki peran mediasi terhadap emotional intelligence dan kinerja (Widiani, 2019). Begitupun studi yang telah dilakukan oleh Hakim \& Pristika (2020) memberikan hasil bahwa $O C B$ berkedudukan sebagai variabel mediasi antara emotional intelligence serta kinerja. Hubungan antar variabel juga digambarkan di Gambar 1.

H4: Diduga organizational citizenship behavior memediasi pengaruh emotional intelligence terhadap kinerja pada dosen Fakultas Ekonomi Universitas Negeri Surabaya.

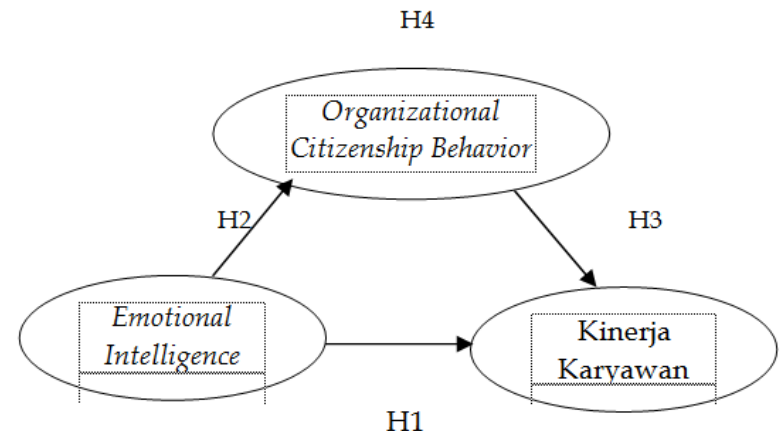

Gambar 1. KERANGKA KONSEPTUAL

\section{METODE PENELITIAN}

Studi ini merupakan jenis penelitian kuantitatif yang menganalisis pengaruh antar variabel emotional intelligence, organizational citizenship behavior, serta kinerja. Data berjenis primer digunakan sebagai sumber data penelitian, yang didapatkan dengan menyebar kuisioner pada Dosen Fakultas Ekonomi Unesa.

Populasi dari penelitian ini ialah dosen Fakultas Ekonomi Unesa berjumlah 98 orang, dengan metode convenience sampling diperoleh 56 responden yang tersebar pada empat Program Studi, yaitu: Manajemen, Akuntansi, Ekonomi Islam, dan Pendidikan Ekonomi. Penelitian ini menggunakan tiga variabel, diantaranya adalah: emotional intelligence (sebagai variabel bebas), kinerja (variabel terikat), serta Organizational Citizenship Behavior (variabel intervening).

Studi ini menggunakan teknik analisis SEM, dengan menggunakan metode pendekatan Partial Least Square (PLS) serta menggunakan bantuan dari software SmartPLS 3.0. Sebelum melakukan analisis PLS, dilakukan suatu pengujian terkait dengan validitas serta reliabilitas yang bertujuan untuk memastikan apakah seluruh item pernyataan dari setiap variabel sudah valid dan reliabel, kemudian dilakukan pula analisis deskriptif yang bertujuan untuk memberikan kemudahan kepada pembaca dalam mengetahui data-data yang telah disajikan.

\section{HASIL DAN PEMBAHASAN}

\section{Uji Validitas}

Tahap pengujian ini bertujuan untuk menetapkan jika indikator yang dipakai telah valid serta dapat mengukur variabel-variabel dalam studi. Dalam studi ini uji validitas dilangsungkan dengan memanfaatkan software Smart PLS 3.0. Indikator dianggap valid jika memiliki nilai korelasi lebih dari 0.70. Akan tetapi, Outer loading yang berkisar 0.50 sampai 0.60 dianggap cukup, bilamana jumlah indikator perkonstruk tidak banyak, yaitu antara tiga hingga tujuh indikator (Chin, 1998 dalam Ghozali, 2014). Berdasarkan hasil olah data, diketahui bahwasanya seluruh indikator mempunyai outer loading yang bernilai lebih dari 0,5. Jadi bisa diartikan bahwa indikator-indikator yang digunakan telah valid dan bisa dianggap sebagai bagian dari ketiga variabel penelitian. 


\section{Uji Reliabilitas}

Composite reliability digunakan untuk menguji nilai reliabilitas yaitu antara blok indikator serta konstruk pembentuknya. Selain itu, tahap uji ini juga dilaksanakan untuk mencari tahu sejauh mana hasil dari pengukuran bisa tetap dikatakan konsisten. Menurut Ghozali (2014), Konstruk dianggap telah reliable jika besar dari nilai composite reliability melebihi 0,70 . Berikut ialah nilai composite reliability dari setiap variabel. Dari hasil olah data penelitian, ditemukan hasil bahwa composite reliability dari ketiga varibel bernilai lebih dari 0,70. Dengan demikian, dapat diartikan bahwasanya model variabel telah sesuai dengan standar composite reliability atau telah memiliki reliabilitas yang baik.

\section{Hasi R-Square (Inner Model)}

Berikut adalah $R$-Square (koefisien determinan) yang dihasilkan oleh pengaruh dari emotional intelligence terhadap kinerja dengan melalui organizational citizenship behavior pada Dosen Fakultas Ekonomi Unesa.

\section{Tabel 1 \\ R-SQUARE}

\begin{tabular}{cc}
\hline Variabel & R-Square \\
\hline Emotional Intelligence & \\
$O C B$ & 0,644 \\
Kinerja & 0,746 \\
\hline
\end{tabular}

Sumber: Output SmartPLS3.0.

Ghozali (2008) memberikan penjelasan terkait dengan nilai $R$-Square, bahwasanya $R$-Square memiliki nilai rendah apabila nilainya berada di bawah 0,33 hingga 0,19 , kemudian memiliki nilai moderate/sedang jika bernilai 0,33 sampai 0,67 , dan bernilai yang kuat ketika memiliki nilai sebesar 0,33 sampai 0,67 .

Pada tabel nomor 1, nilai $R$-Square dari model pengaruh emotional intelligence terhadap kinerja adalah 0,746. Dari besarnya hasil tersebut, dapat di interpretasikan bahwasanya variabel emotional intelligence menjelaskan variabel konstruk kinerja sebesar 74,6\%. Sedangkan variabel lain atau variabel yang tidak terdapat dalam penelitian, mampu memberikan penjelasan terkait dengan kinerja dosen Fakultas Ekonomi Universitas Negeri Surabaya sebesar 25,4\%. Ini berarti bahwa konstruk emotional intelligence menunjukkan model tinggi terhadap kinerja.

Tabel 1 juga menunjukkan bahwa $R$-Square dari pengaruh emotional intelligence terhadap $O C B$ bernilai 0,644 . Jadi bisa diartikan bahwasanya variabel konstruk $O C B$ dijelaskan oleh variabel emotional intelligence dengan besar $64,8 \%$, sedangkan variabel lain di luar penelitian ini dapat memberikan penjelaskan terkait dengan perilaku $O C B$ dosen Fakultas Ekonomi Universitas Negeri Surabaya sebesar $35,2 \%$. Hal ini dapat diartikan bahwasanya konstruk emotional intelligence menunjukkan model sedang (moderate) terhadap $O C B$.

\section{Hasil Uji T (Signifikan)}

Tahap Uji ini dijalankan dengan tujuan untuk memeriksa terkait ada ataupun tidaknya efek yang bersifat signifikan dalam hubungan antar variabel. Diartikan signifikan jika nilai t-hitung melebihi 1,96 (>1,96) atau nilai $P$-value adalah kurang dari 0,05 ( <0,05) (Ghozali, 2014).

Nilai output t-statistics dari pengaruh emotional intelligence terhadap kinerja yaitu 2,309 $(>1,96)$. Bermakna jika terdapat pengaruh yang bersifat signifikan diantara variabel emotional intelligence terhadap kinerja. Output koefisien estimate-nya ialah 0,374. Koefisien itu bertanda positif (menggambarkan perbandingan lurus), yang dapat dimaknai bahwa ketika terjadi peningkatan pada emotional intelligence, semakin meningkat pula kinerja, begitupun berlaku untuk keadaan sebaliknya. 
Inas Khildah Fatmawati \& Nurul Indawati. Peran Organizational Citizenship Behavior sebagai Variabel Mediasi Pengaruh Emotional Intelligence terhadap Kinerja di Fakultas Ekonomi Universitas Negeri Surabaya

Tabel 2

PATH COEFFICIENT

\begin{tabular}{llllc}
\hline \multicolumn{1}{c}{ Hubungan antar Variabel } & $\begin{array}{c}\text { Original } \\
\text { Sampel }\end{array}$ & $\begin{array}{c}\text { T- } \\
\text { Statistics }\end{array}$ & \multicolumn{2}{c}{ Keterangan } \\
\hline Emotional Intelligence $\rightarrow$ Kinerja & 0,374 & 2,309 & $\geq 1,96$ (Signifikan) & Hipotesis Diterima \\
Emotional Intelligence $\rightarrow O C B$ & 0,802 & 15,147 & $\geq 1,96$ (Signifikan) & Hipotesis Diterima \\
$O C B \rightarrow$ Kinerja & 0,534 & 3,303 & $\geq 1,96$ (Signifikan) & Hipotesis Diterima \\
\hline
\end{tabular}

Sumber: Output Smart PLS3.0.

Pengaruh variabel emotional intelligence terhadap organizational citizenship behavior menghasilkan $t$ statstics senilai 15,147 (>1,96). Hasil tersebut menujukkan adanya pengaruh signifikan yang terdapat diantara variabel kecerdasan emosional dengan $O C B$. Sedangkan nilai dari koefisien estimate adalah 0,802. Nilai koefisien yang bertanda positif mengandung arti bahwa apabila tingkat emotional intelligence semakin membaik, maka $O C B$ juga akan semakin baik pula, begitupun untuk sebaliknya.

Selanjutnya pengaruh dari organizational citizenship behavior terhadap kinerja menghasilkan nilai $t$ statistics dengan besar 3,303 (>1,96), dapat diartikan bahwa terdapat pengaruh signifikan antar variabel $O C B$ terhadap variabel kinerja. Output koefisien estimate bernilai 0,534. Tanda positif dari koefisien tersebut berarti bahwa dengan semakin tingginya tingkat $O C B$, akan berdampak pada semakin tingginya tingkat kinerja, begitu juga untuk sebaliknya. Dari pembahasan di atas, diketahui bahwa pengaruh antar variabel bersifat positif, emotional intelligence berpengaruh signifikan terhadap kinerja secara langsung, emotional intelligence berpengaruh signifikan terhadap organizational citizenship behavior secara langsung, dan $O C B$ berpengaruh signifikan terhadap kinerja secara langsung.

Adapun pengaruh secara tidak langsung antara emotional intelligence terhadap kinerja dengan melalui organizational citizenship behavior, diterangkan pada tabel 3. Nilai koefisien pengaruh langsung antara emotional intelligence pada kinerja adalah 0,374 dan nilai $t$-statistic $2,309(\geq 1,96)$ yang bermakna signifikan. Adapun pengaruh secara tidak langsung emotional intelligence terhadap kinerja dengan melalui $O C B$ ialah 0,429 dan $t$-statistic $3,219(\geq 1,96)$, artinya adalah signifikan. Dari hasil tersebut, dapat diketahui bahwa emotional intelligence dapat memberikan berpengaruh langsung dan tidak langsung terhadap kinerja dengan melalui $O C B$. Sehingga, organizational citizenship behavior memberikan efek memediasi pada pengaruh emotional intelligence terhadap kinerja dosen Fakultas Ekonomi Unesa.

Tabel 3

INDIRECT EFFECT

\begin{tabular}{lcccc}
\hline \multicolumn{1}{c}{ Path } & $\begin{array}{c}\text { Original } \\
\text { sampel (O) }\end{array}$ & t-statistic & & \multicolumn{2}{c}{ Keterangan } \\
\hline Emotional intelligence $\rightarrow$ Kinerja & 0,374 & 2,309 & $\geq 1,96$ & Signifikan \\
Emotional intelligence $\rightarrow$ Organizational & 0,429 & 3,219 & $\geq 1,96$ & Signifikan \\
Citizenship Behavior $\rightarrow$ Kinerja & & & & \\
\hline Sum & & & & \\
\hline
\end{tabular}

Sumber: Output Smart PLS 3.0

\section{Pengaruh Emotional Intelligence terhadap Kinerja}

Menurut hasil analisis yang telah dilakukan, diketahui bahwa emotional intelligence memberi pengaruh positif signifikan terhadap kinerja. Berdasarkan hasil pengamatan yang telah dilakukan, ini terjadi karena dosen Fakultas Ekonomi Universitas Negeri Surabaya memiliki motivasi diri yang tinggi, sehingga dosen FE Unesa cenderung terdorong untuk mencoba yang lebih baik dari yang pernah dihasilkan sebelumnya. Selain itu dosen Fakultas Ekonomi Unesa juga bisa memahami emosi yang dimiliki oleh rekan kerjanya, meskipun kemampuan tersebut tergolong dalam kategori cukup. Oleh karena itu, tentu saja dua hal yang telah diuraikan sebelumnya dapat memberikan dampak yang sangat baik terhadap kinerja yang diberikan oleh dosen FE Unesa, baik melalui dorongan dari dalam diri sendiri berupa motivasi, maupun kemampuan untuk memahami emosi pekerja lain dan menyesuaikan 
diri dalam menyikapi emosi tersebut, maka $\mathrm{H} 1$ diterima. Hasil dari studi ini serupa dengan temuan yang didapatkan oleh Eze, et al. (2019), bahwa didapati suatu pengaruh positif signifikan antara emotional intelligence terhadap Kinerja Karyawan. Penelitian tersebut menguji pengaruh antar dua variabel yaitu emotional intelligence (independent variable) dan kinerja karyawan (dependent variable). Hasil penelitian lainnya oleh Chong, et al. (2020) menjelaskan bahwa emotional intelligence memberikan pengaruh positif serta signifikan pada kinerja karyawan. Al-Qeed, et al. (2018) dalam studinya juga mendapati bahwa terdapat hubungan yang positif diantara variabel penelitiannya yaitu emotional intelligence dan organizational performance. Namun, hasil dari penelitian ini berlawanan dengan penelitian Madali, et al.(2014) yang memberikan hasil temuan yang berbeda, di mana hasilnya adalah tidak ada pengaruh diantara emotional intelligence dengan kinerja karyawan.

\section{Pengaruh Emotional Intelligence terhadap Organizational Citizenship Behavior}

Emotional intelligence memberikan pengaruh positif dan signifikan pada organizational citizenship behavior. Hasil ini sesuai dengan hasil pengamatan yang dilakukan, bahwa dosen FE Unesa cenderung memiliki kemampuan yang cukup baik dalam memahami apa yang dirasakan orang lain, sehingga dapat memunculkan sikap organizational citizenship behavior. Selain itu, peningkatan perilaku organizational citizenship behavior dosen FE Unesa juga disebabkan oleh sikap kesadaran diri yang dimiliki. Ketika emosi diri dapat terkontrol dengan baik dan kesulitan yang dihadapi dapat ditangani secara reasional, maka akan menjadi lebih mudah dalam menyelesaikan tugas sesuai peran maupun di luar peran yang harus dilakukan. Dalam hal ini, H2 diterima. Hasil yang didapat dari penelitian ini memiliki kesesuaian hasil dengan studi yang telah dilaksanakan oleh (Luxmi \& Vashisht, 2017) yang menyebut bahwa emotional inteliigence memengaruhi organizational citizenship behavior secara positif dan signifikan. Fokus dari penelitian tersebut adalah pengaruh antar dua variabel yaitu kecerdasan emosional (independent variable) dan organizational citizenship behavior (dependent variable). Sabahi \& Dashti (2016) dalam penelitiannya juga menyebutkan jika kecerdasan emosional memberi pengaruh positif serta signifikan terhadap organizational citizenship behavior. Aderibigbe \& Mjoli (2018) juga menemukan bahwa kecerdasan emosional berhubungan positif serta signifikan dengan $O C B$. Akan tetapi hasil dari studi ini memiliki perberbedaan dengan hasil studi dari Nurfadilah (2019), bahwa emotional intelligence tidak berpengaruh signifikan terhadap $O C B$.

\section{Pengaruh Organizational Citizenship Behavior terhadap Kinerja}

Kinerja dipengaruhi oleh organizational citizenship behavior secara positif dan signifikan. Hasil tersebut terbukti dengan adanya sikap sportif yang dimiliki oleh dosen Fakultas Ekonomi Unesa dalam bekerja, dosen Fakultas Ekonomi Universitas Negeri Surabaya selalu berusaha memberikan yang terbaik bagi institusi dan berusaha untuk tidak mencari masalah di tempat kerja, sehingga dapat memberikan dampak yang baik pada peningkatan kinerja. Sehingga, H3 diterima. Temuan ini memberikan dukungan pada penelitian sebelumnya dari Razavi \& Attarnezhad (2018) yang menyatakan bahwa ditemukan adanya pengaruh signifikan positif dalam hubungan antara $O C B$ dengan kinerja. Dalam penelitiannya menggunakan variabel komunikasi, motivasi, kinerja, dan $O C B$. Hasil lain dari penelitian Gunay (2018) mengemukakan bahwa $O C B$ memberikan pengaruh positif serta signifikan terhadap employee performance. Begitu pula penelitian dari Priyono, et al. (2019) yang memaparkan hasil bahwa $O C B$ memengaruhi employee performance secara positif serta signifikan. Namun temuan ini berlawanan dengan penelitian Hanzaee \& Mirvaisi (2013) yang tidak mendapati adanya pengaruh antara OCB terhadap employee performance.

\section{Pengaruh Emotional Intelligence terhadap Kinerja mediasi Organizational Citizenship Behavior}

Emotional intelligence memiliki pengaruh signifikan positif terhadap kinerja dengan melalui organizational citizenship behavior. Hubungan antara emotional intelligence terhadap kinerja dengan melalui $O C B$ memiliki pengaruh yang hasilnya lebih tinggi jika dibanding dengan nilai dari pengaruh langsungnya. Sehingga dapat diambil kesimpulan bahwasanya $O C B$ berkedudukan menjadi variabel mediasi dalam hubungan antara emotional intelligence dengan kinerja. Hal ini sesuai dengan kenyataan bahwa dosen yang memiliki kepekaan emosi yang baik terhadap dosen lain cenderung akan memberikan tanggapan yang sesuai dengan emosi tersebut dan terdorong untuk melalukan perilaku $O C B$, yang pada akhirnya akan memberikan dampak baik terhadap kinerja yang diberikan. Sehingga, 
Inas Khildah Fatmawati \& Nurul Indawati. Peran Organizational Citizenship Behavior sebagai Variabel Mediasi Pengaruh Emotional Intelligence terhadap Kinerja di Fakultas Ekonomi Universitas Negeri Surabaya

H4 diterima. Hasil yang sudah diperoleh dalam penelitian ini mempunyai kesamaan dengan hasil dari studi lain yang sebelumnya telah dilaksanakan oleh Widiani (2019), didapatkan suatu hasil bahwa organizational citizenship behavior memediasi hubungan antara emotional intelligence dengan employee performance. Begitu pula penelitian dari Hakim \& Pristika (2020) yang memberikan hasil bahwa $O C B$ berkedudukan sebagai variabel mediasi antara emotional intelligence dan performance.

\section{KESIMPULAN}

Berdasarkan pada hasil dari proses pengolahan data serta pembahasan hasil studi yang telah disebutkan, maka peneliti dapat memberikan beberapa point kesimpulan, yaitu: Pertama, emotional intelligence mempunyai pengaruh signifikan positif terhadap kinerja. Mengandung arti bahwa emotional intelligence yang tinggi akan menghasilkan kinerja yang tinggi pula, emotional intelligence memberikan pengaruh besar pada kinerja; Kedua, emotional intelligence memiliki pengaruh positif dan signifikan terhadap organizational citizenship behavior. Ini berarti bahwa semakin baik tingkat emotional intelligence maka akan semakin baik pula $O C B$, emotional intelligence memiliki pengaruh yang besar terhadap $O C B$; Ketiga, organizational citizenship behavior memberikan pengaruh yang signifikan positif terhadap kinerja. Hal tersebut dapat dimaknai bahwa ketika terjadi peningkatan $O C B$ maka kinerja juga cenderung meningkat, serta pengaruh dari $O C B$ terhadap kinerja tergolong besar; Keempat, emotional intelligence memberi pengaruh signifikan positif terhadap kinerja melalui $O C B$. Dari hasil tersebut, dapat diketahui bahwasanya Emotional intelligence yang baik akan berdampak pada baiknya perilaku organizational citizenship behavior, sehingga kinerja dapat ditingkatkan. Pengaruh emotional intelligence terhadap kinerja dengan melalui organizational citizenship behavior bernilai lebih tinggi jika dibanding dengan pengaruh langsungnya. Sehingga bisa disimpulkan bahwa variabel $O C B$ benar-benar berperan menjadi variabel intervening. Kemudian terdapat suatu keterbatasan yang juga dimiliki oleh penelitian ini, yaitu terkait dengan sampel penelitian yang hanya sebanyak 56 orang responden yang bekerja sebagai dosen Fakultas Ekonomi Unesa. Untuk penelitian kedepannya disarankan agar dapat menambah jumlah sampel sehingga hasil yang didapatkan bisa lebih terglobalisasi dan juga penelitian selanjutnya diharapkan bisa mengembangkan studi ini dengan menambahkan variabel lain yang merupakan bagian dari kecerdasan yang dimiliki oleh individu yang juga dapat mempengaruhi kinerja, yaitu kecerdasan intelektual maupun kecerdasan spiritual.

\section{DAFTAR PUSTAKA}

Aderibigbe, J. K., \& Mjoli, T. Q. (2018). Occupational Stress as a Correlate of Organisational Citizenship Behaviour and Psychological Capital Among Graduate Employees in Nigeria. European Review Of Applied Sociology, 11(16), 51-62. https://doi.org/10.1515/eras-2018-0005

Al-Qeed, M. A., Abdul Halim Khaddam, A., Al-Azzam, Z. F., \& Abd El Fattah Atieh, K. (2018). The effect of talent management and emotional intelligence on organizational performance: Applied study on pharmaceutical industry in Jordan. Journal of Business \& Retail Management Research, 13(01), 0-14. https://doi.org/10.24052/jbrmr/v13is01/art-01

Bestyasamala, E. (2018). the Influence of Emotional Intelligence and Organizational Citizenship Behavior Towards Officer Performance With the Organization and Religiosity As a Moderating Variable (Study on the Employees of the Education and Culture Department in Demak). International Journal of Islamic Business Ethics, 3(1), 423. https://doi.org/10.30659/ijibe.3.1.423-436

Chelagat, L. J., Chepkwony, P. K., \& Kemboi, A. (2015). Effect of organizational citizenship behavior on employee performance in banking sector, Nairobi County, Kenya. International Journal of Business, Humanities and Technology, 5(4), 55-61.

Chong, S. C., Falahat, M., \& Lee, Y. S. (2020). Emotional intelligence and job performance of academicians in Malaysia. International Journal of Higher Education, 19(1), 69-80. 
https://doi.org/10.5430/ijhe.v9n1p69

Eze, B. U., Adelekan, A. S., Ojo, O. J., \& Erigbe, P. A. (2019). Emotional Intelligence and Job Performance of Frontline Employees of Selected Microfinance Banks. Management Science Review, 10(1), 2019. https://www.uniben.edu

Fitria Rokhmah Nurfadilah. (2019). Employee Engagement Terhadap Organizational Citizenship ( Studi Pada Guru Madrasah Tsanawiyah Negeri 7 Kebumen ) Fitria Rokhmah Nurfadilah Jurusan Manajemen Konsentrasi Sumber Daya Manusia Sekolah Tinggi Ilmu Ekonomi Putra Bangsa Kebumen Email : fitriarok.

Ghozali, I. (2008). Structural Equation Modeling: Metode Alternatif Dengan Partial Least Square (PLS) (4th Ed.). Badan Penerbit Universitas Diponegoro.

Ghozali, I. (2014). Structural Equation Modeling: Metode Alternatif Dengan Partial Least Square $(P L S)$ (Edisi Keempat) (Edisi Keem). Badan Penerbit Universitas Diponegoro.

Günay, G. Y. (2018). Relationship between Job Satisfaction , Organizational Citizenship Behavior and Employee Performance: Sample of Edirne Financial Office Employees in Turkey. American International Journal of Contemporary Research, 8(1), 64-65.

Hakim, \& Pristika. (2020). the Influence of Emotional Intelligence on Organizational Commitment and Organizational Citizenship Behavior. Journal of Social Science Research, 1(1), 5-8. https://doi.org/10.24297/jssr.v1i1.6674

Hakim, W., \& Fernandes, A. (2017). Journal of Organizational Change Management Moderation effect of organizational citizenship behavior on the performance of lecturers For Authors Moderation effect of organizational citizenship behavior on the performance of lecturers. Journal of Organizational Change Management, 11-2016. https://doi.org/10.1108/JOCM-11-2016-0242

Heidarzadeh Hanzaee, K., \& Mirvaisi, M. (2013). A survey on impact of emotional intelligence, organizational citizenship behaviors and job satisfaction on employees' performance in Iranian hotel industry. Management Science Letters, 3, 1395-1402. https://doi.org/10.5267/j.msl.2013.04.010

Khan. (2018). Influence of Individual Emotional Intelligence Dimension on Employee Performance Working in Banks Rao Aamir Khan 1, Syed Zain Bukhari 2, Asad Afzal Humayon 3, Muhammad Majid Khan 4. 9, 606-627.

Khanifah, \& Palupiningdyah. (2015). Pengaruh Kecerdasan Emosional Dan Budaya Organisasi Pada Kinerja Dengan Komitmen Organisasi. Management Analysis Journal, 4(3), 200-211. https://doi.org/10.15294/maj.v4i3.8871

Lakshmi, K. N., \& Rao, K. S. S. (2018). A study on role of emotional intelligence on employee performance. International Journal of Civil Engineering and Technology, 9(3), 440-448.

Luxmi, \& Vashisht, A. (2017). Impact of Emotional Intelligence on Organization Citizenship Behaviour: A Study among Nurses of Government and Private Hospitals in and around Chandigarh. Amity Journal of Training and Development, 2(1), 1-18.

Madali, C., Purnama, E. D., Ekonomi, F., Kristen, U., \& Wacana, K. (2014). Pengaruh Emotional Quotient (Eq) Terhadap Gaya Kepemimpinan, Stres Kerja , Dan Kepuasan Kerja Dalam Meningkatkan Kinerja Karyawan Di Pt . Karya Teknik Makmur. 9-18.

Mustika Wati, D., \& Surjanti, J. (2018). Pengaruh Kecerdasan Emosional, Organizational Citizenship 
Inas Khildah Fatmawati \& Nurul Indawati. Peran Organizational Citizenship Behavior sebagai Variabel Mediasi Pengaruh Emotional Intelligence terhadap Kinerja di Fakultas Ekonomi Universitas Negeri Surabaya

Behavior (OCB) dan Kepuasan Kerja Terhadap Kinerja Karyawan pada PT PLN (Persero) Area Bojonegoro. Jurnal Ilmu Manajemen (JIM), 6(4).

Noermijati, S., \& Ratri, I. K. (2018). on Employee Performance Mediated By Cooperative Conflict Management Style. Journal of Applied Management (JAM) Volume 17 Number 1, 30, 37-47.

Priyono, B. S., Cahyaningsih, E., Indriyaningrum, K., \& Putra, A. B. (2019). The Role of Organizational Citizenship Behavior as an Intervening Variable in the Influence of Servant Leadership and Employee Engagement on Performance. 100(2011), 645-650. https://doi.org/10.2991/icoi19.2019.113

Razavi, S. H., \& Attarnezhad, O. (2018). International Journal of Business and Social Science. Management of Organizational Innovatio, 1(1), 226-232. http://www.ijbssnet.com/journals/Vol_4_No_1_January_2013/26.pdf

Sabahi, A. H., \& Sanai Dashti, N. (2016). The effect of emotional intelligence and job satisfaction on organizational citizenship behavior. Management Science Letters, 7(2), 475-480. https://doi.org/10.5267/j.msl.2016.6.001

Sharma, K., \& Mahajan, P. (2017). Relationship Between Emotional Intelligence and Organisational Citizenship Behaviour Among Bank Employees. Pacific Business Review International, 9(11), $20-29$.

Suwibawa, A., Agung, A. A. P., \& Sapta, I. K. S. (2018). Effect of Organizational Culture and Organizational Commitment to Employee Performance through Organizational Citizenship Behavior (OCB) as Intervening Variables (Study on Bappeda Litbang Provinsi Bali). International Journal of Contemporary Research and Review, 9(08), 20997-21013. https://doi.org/10.15520/ijcrr/2018/9/08/582

Vipraprastha, T., Sudja, I. N., \& Yuesti, A. (2018). The Effect of Transformational Leadership and Organizational Commitment to Employee Performance with Citizenship Organization (OCB) Behavior as Intervening Variables (At PT Sarana Arga Gemeh Amerta in Denpasar City). International Journal of Contemporary Research and Review, 9(02), 20503-20518. https://doi.org/10.15520/ijcrr/2018/9/02/435

Widiani, N. P. (2019). The effect of love of money and emotional intelligence on employee performance with organizational citizenship behavior as mediating variable. International Research Journal of Engineering, IT \& Scientific Research, 5(1), 39-49. https://doi.org/10.21744/irjeis.v5n1.596

Unesa.ac.id. 2020. Selayang Pandang. (https://www.unesa.ac.id/page/tentang-unesa/selayang-pandang. Diakses Pada 17 Mei 2020). 